\title{
Business students' perspectives: What makes successful group performance?
}

\author{
Rinny Rantung, Reggy Sarmita
}

Department of Management, Universitas Klabat, Indonesia

\begin{tabular}{l} 
Article Info \\
\hline Article history: \\
Received Feb 12, 2020 \\
Revised Aug 14, 2020 \\
Accepted Sep 18, 2020 \\
\hline
\end{tabular}

Keywords:

Business students

Cohesiveness

Group performance

Teamwork

\begin{abstract}
Purpose of this study was to identify factors contributing to the successful group performance from the perspective of business students. The in-depth interview was done followed by a survey derived forty-five items variables, after some tests 21 items variables removed due to low item remainder coefficient resulted in 24 items questionnaires. A total of 355 respondents participated during the survey. Exploratory factor analysis with principal factor extraction was performed and five contributing factors were extracted. Those factors are cohesiveness, inter-relationship, norms, diversity and appointed of team leader.
\end{abstract}

This is an open access article under the CC BY-SA license.

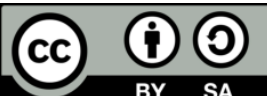

\section{Corresponding Author:}

Reggy Sarmita,

Department of Management,

Universitas Klabat,

Jl. Arnold Mononutu, Airmadidi 95371, Minahasa Utara, Sulawesi Utara, Indonesia.

Email: rsarmita@unklab.ac.id

\section{INTRODUCTION}

The purposes of higher education is to prepare graduates to have knowledge, skills and capabilities for their future career, in reaching that objectives educators are engaging teamwork class activities to prepare graduates for success in the real world working environment [1]. The ability to work within teams is an essential soft-skills which is still very high in demand nowadays [2]. Corporations are spending a big amount of money in training their employees, and expecting those employees to have the teamwork ability to reach companies required business outcomes, but they are not gaining the return they expected [3]. Accordingly, Shola, et al. [4] mentioned that every employeer wants their employee to be ready for work and have particular skill needed by the employer. Self-Critical, Creativity, ability to generate good ideas, leadership skills are the factor that needed by the employer but lack in graduates nowadays [5].

Teamwork pedagogy teaching tool are design and developed in relevant to the expectation of the corporation, which is to prepare graduates to be ready for professional working environment [6]. Further said, that teamwork pedagogy is widely recognized and considered as a teaching tool to enhance soft-skills development that take into consideration the benefit and cost in delivering the expected outcome of employer.

According to McMurray, et al. [2], most of the employer expect that their employees build up soft skills such as; communication skill, presentation skill, trustworthiness, reliability and having desire to learn something new. Besides, Sugito, et al. [7] found that communication skills, confidence, courage, and responsibilities skills are enhanced by group work and activities. In response, some studies come up with other important soft-skills, that students might be able to incorporate by teamwork; The first one is the 
capability to give a positive reaction in a different situation. Second, is the ability to find solutions when conflict occurred, which has a big impact in responding to the working situation deals with internal conflict and disagreements. Third, is goal achievement, this is a skill that students might not realize they are learning while doing teamwork activities, but very important in a business situation [8-10]. Moreover, sense of goal achievement might lead to the ability in demonstrating guidelines, rules and requirements in the area of team members to attain set goals [9].

Studies found that working in group develop critical thinking, creativity, and enhance social and communicative skills, that are positive outcomes of group work [11,12]. Furthermore, students prefer to study in the group because it is fun and enjoyable [13]. Moreover, group work could also give students more experience in face-to-face interaction. Despite all the advantages that students might get from teamwork activities, some studies found that arranging classroom activities and curriculum that incorporates teamwork is a challenging situation for teachers as well as students [14, 15]. Educators must able to understand the obstruction that commonly experienced by students in a group setting before assigning them into group work [16]. Hence, teamwork instruction strategy must be well planned and design properly to have the best potential outcomes necessary for the students.

Group learning affected the way teaching and learning strategies being delivered in the classroom because group learning is critical in building students' wellbeing for their future careers [17]. Further said, that incorporating technology in group learning is also an important thing to consider, but the teachers must be responsible for choosing the right technology that contributes to students learning in preparing them to have real-life skills. Likewise, Curşeu and Pluut [18] added that teachers should be responsible for composing group work that enhances the ability of the students to enter the changing working environment.

The changes in the business environment have an impact on the new pedagogical form of education necessary for students to have the skills and abilities needed by the employer [19]. Even in the modern education environment, individual preferences such as comfort level, knowledge, and competence level are still important to consider in forming a group work. Thus, in designing group work, lecturers must also understand the mechanism of each group structure, and consider other details such as creativity, cohesiveness, and group performance [20].

On the other hand, studies indicate that even though teachers are expert in planning and designing team based pedagogical learning method, not all students are gaining the advantages of those learning experience $[6,21]$. Furthermore, students have different perspective in the benefit that they are experiencing from teamwork pedagogical teaching. The students that are used to the instructional teaching method have experiencing less benefit compare to students that are used to the team-based learning. According to social identity theory by Ashforth and Mael [22], each perspective of belongingness to a group and individual engagement in a group tend to shape their satisfaction in a group formation. Correspondingly, student's selfperspective on their capability as a group member and their academic achievement affected their anxiety and avoidance in the involvement with a group work [23].

A study by Hwang [24] found that total involvement of group members contributes to the teamwork quality. Moreover, interpersonal interaction between team members and the balance of team member expertise are the key factor that contribute to the teamwork quality and teamwork performance. However, another study Meslec and Curşeu [25] found that group balance negatively connected to the teamwork quality and tend to create more task conflict. Thus, deteriorate the interpersonal relationship within group that leads to low performance of group work. Correspondingly, group work with many members dominate the leadership, tend to deteriorate group performance [1]. Another study found that a group consist of friendship member may solve the conflict better than just an acquaintances group member [26]. In addition, team cohesiveness, mutual trust and complementary support, are key factors in building teamwork performance [27]. On the other hand, study found that team cohesiveness does not automatically contributes to the group effectiveness [28].

Studies on teamwork and group performance had been done on how to design curriculums offered in higher education. However, the study of Hoegl and Gemuenden [29] suggested that some further studies need to be done in regard to the perspective of a successful team performance. Moreover, few studies had been done concerning successful group performance from the perspective of business students. The purpose of this study is to identify factors that contributing to the successful group performance from business students' perspectives. Particularly to answer the following research questions: 1) What factors contributes to the successful group performance? 2) Which of those factors account for the most variance? Hopefully, the result of this study can give a valuable contribution to teamwork development as a teaching and learning tool, to enhance better group performance in business schools or might be in other schools as well. 


\section{RESEARCH METHOD}

This study employed quantitative and qualitative approach. Quantitative approach is used to find the factor connected to the successful group performance, and qualitative approach is use when gathering data for pilot testing. Sixteenth students are consented to participate in the interview, and in-depth interviews conducted with those 16 students are recorded and transcribed in gathering more information from the business students on their perspectives about successful group performance. The number of people that were interviewed is based on the saturation of information gathered. There was no other new information given by the fifteenth and sixteenth person. 45 items are gathered during interviewed and some other literature studies. After constructed the 45 items then continue with the test of reliability and validity of the items to 60 students, resulted 24 items. 21 items were removed due to low quality of item-remainder coefficient less $0.6[30]$.

The valid questionnaire with 24 items was then distributed to respondents using google form. The respondents of this study are undergraduate business students of Unversitas Klabat. Business students at Universitas Klabat are coming from different part of Indonesia. Indonesia is a multicultural nation, meaning the students in Univeristas Klabat came from different cultures of Indonesia. Purposive sampling method was used in selecting respondents. The respondents were selected based on the criteria of the subject that they are taking in that semester, which required more groupwork activities. Those subjects are strategic management and planning, financial management and policy, and introduction to entrepreneurship subject. Those subjects were taken by 3rd dan 4th years business students. There are 361 business students of Universitas Klabat participated in this study, but not all participant responded each question consistently. Six respondents were removed from the data and 355 data respondents were used in analysis.

To answer the first research question, we examine the value of Kaiser-Meyer-Olkin (KMO) test of sampling adequacy which recommended value $>0.5$ as acceptable value, and Bartlett's test of sphericity with $\mathrm{p}<0.05$ to check whether the factor analys is appropriate for the data [31]. Next research question is to represent the variance, in answering the second research question; we use the unique variance method where the percentage variance represents how much the contribution of each factor to the total variance.

\section{RESULTS AND DISCUSSION}

In answering the research questions of "what factors contributes to the successful group performance?" and "which factors are accounts of the most variance to the successful group performance?" An exploratory factor analysis was performed using SPSS. The result shows that the value of KMO is .914 which is greater than 0.5 and Bartlett's test of sphericity $\mathrm{p}=0.000$ means the dataset is suitable for factor analysis.

To interpret factor analysis, first, we look only at the factor that is meaningful for interpretation and analysis from the rotated eigenvalues and scree-plot. Rotated eigenvalue and scree-plot help us to determine the number of factors that are significant to retain. Next, we check the extracted communalities to measure the internal consistency of those factors using Cornbach's Alpha. Then, we continue with the varimax rotation suppressing the factor loading to the small coefficient, to see whether the factor loading in each factor is desirable for interpretation and to continue in naming those factor. To give names to the factors we look at the variables within the factors that are the best representation of those factors. For unique variance in factor analysis, we see form the percentage of variance after varimax rotation that tells how much each factor contributed to the total variance.

Based on the result in Table 1 the total initial eigenvalues, Total Extracted sum of squared loading, and Rotation sum of squared shows that 5 factors that have eigenvalues $>1$, means there are 5 factors to retain. The scree-plot test in Figure 1 also gives the same indication amount of factor that is meaningful to retain from the data points that are above the break. The break is the drawing of the end of the vertical line to the horizontal line in a curve. The scree test shows the breakpoints at the fifth component factor.

Table 1. Total variance explained

\begin{tabular}{cccc}
\hline $\begin{array}{c}\text { Component } \\
\text { factor }\end{array}$ & $\begin{array}{c}\text { Total initial } \\
\text { eigenvalue }\end{array}$ & $\begin{array}{c}\text { Extracted sum of } \\
\text { square loading }\end{array}$ & $\begin{array}{c}\text { Rotation sum of } \\
\text { squared }\end{array}$ \\
\hline 1 & 9.262 & 9.262 & 4.663 \\
2 & 2.032 & 2.032 & 3.534 \\
3 & 1.711 & 1.711 & 3.390 \\
4 & 1.169 & 1.169 & 2.065 \\
5 & 1.021 & 1.021 & 1.545 \\
\hline
\end{tabular}




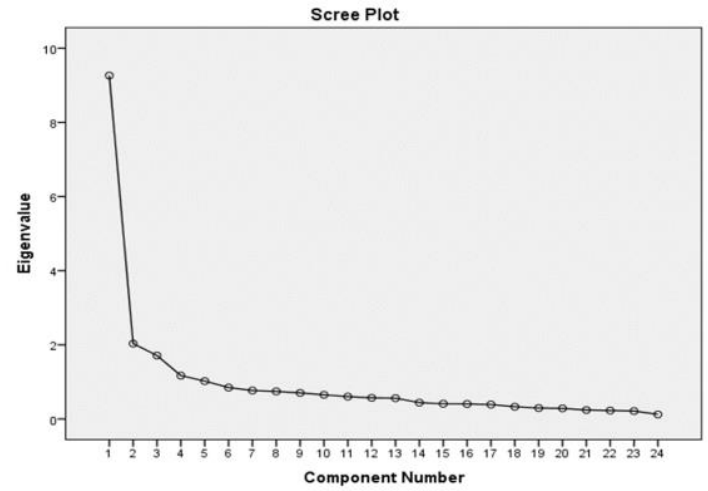

Figure 1. Scree-plot test

According to the result of Eigenvalues and scree-plot test, a set of five numbers of factors are retained. However, we need to check the extracted communalities to measure internal consistency of those factors. From those five factors extracted, one factor had the value of Cornbach's alpha measure of internal consistency less than 0.7, and four factors measure of internal consistency are well defined as shown by reliability score of Cronbach's Alpha that is more than 0.7 [31]. Those factors that contribute to the successful group performance are named based on the variable within the factor that are best represents each factor. The variable that is best represents the factor shown in Table 3 Factor extracted after varimax rotation. The names of those factors as shown in Table 2 are as follows; 1) Cohesiveness, 2) Inter-relationship, 3) Norms and Ethics, 4) Diversity, 5) Team Leader.

Table 2. Factor extracted: Cronbach's alpha measure of internal consistency

\begin{tabular}{ccc} 
Factor & Name of the factor & Cornbach Alpha \\
\hline Factor 1 & Cohesiveness & .891 \\
Factor 2 & Inter-Relationship & .846 \\
Factor 3 & Norms & .841 \\
Factor 4 & Diversity & .758 \\
Factor 5 & Appointed Team Leader & .399 \\
\hline
\end{tabular}

The loading of variables on factors is shown in Table 3. All the variables are group by the size of factor loading that represents the best fit for each factor. Any factor loading that has value below 0.4 are removed as suggested by Field [31] that substantial loading is above 0.4. As shown in Table 3, variable X9 group members are active in the open discussion has factor loading $\mathrm{r}=.757$, and X10 group members are free to share their opinion has factor loading $r=.729$. Those variables have the highest loading for factor 1 . Those results give the indication that the groups in which the members are active in the open discussion and free to share their opinions are the group that cohesive. In addition, higher level of tolerant, active in sharing ideas, shared responsibility and strong motivation of group members are indications of cohesiveness. That means group cohesiveness is one of factor that is important to consider in obtaining successful group performance. For the variables that best represent factor 2 are X2, X1, X3, X4 and X6. The relationship among group $(\mathrm{X} 1)$ has factor loading $(\mathrm{r}=.815)$, and $(\mathrm{X} 2)$ the relationship between group member and leader has factor loading $(r=.856)$. From those variables that have the highest loading factor, we can see that interrelationship in a group has also contributed in successful group performance.

Good self-management X19 has factor loading $(\mathrm{r}=.786)$ and X20 self-control has the second highest factor laoding $(r=.748)$ that account for factor 3 . Self management and self control are typical behavior standard that needed by a group in order to have good performance, that makes "Norms" is the best name that represents factor 3. For the fourth factor, the highest factor loading is X23 different culture ( $\mathrm{r}=$ $.867)$ and $\mathrm{X} 24$ different skills $(\mathrm{r}=.837)$ among group member are account for the highest loading, that means diversity is also considered as one of the factor that has contribution in the successful group performance from the perspective of business students. Group leader appointed by lecturers $(r=.719)$ and outsider mentor $(\mathrm{r}=.697)$ are the item variables that build factor 5 . In naming factor 5 we see the best words that represents by the variables within the factor and we choose to name factor 5 as "Appointed Team Leader" that means from the perspective of business students in Indonesia, particularly in Universitas Klabat, the team leader that pointed by lecturer or mentor is considered as one of the factor that contributes in the successful group

Business students' perspectives: What makes successful group performance? (Rinny Rantung) 
performance. This factor 5 has only consist on two items variable whereas in determining the factor to retain, those factor that have less than three variables are considered as less desireable. However, the general rule in determining the factor is also taking into consideration many aspect in relation to the individual factor, not only look at the items variable but also consider the rotated factor loading and the absolute sample size [32]. The factor loading of the items in factor 5 are greater that 0.4 and for this study the sampel size are greater than 300. According to Yong and Pearce [32] in the interpretation of factor loading the largest loading item can be retained assuming that that the items is a latent nature of the variable. Moreover, the greater the sample size allowing the factor to be consider significant and meaningful for the interpretation.

Table 3. Factor extracted after varimax rotation

\begin{tabular}{|c|c|c|c|c|c|c|}
\hline & \multicolumn{5}{|c|}{ Factor } \\
\hline & & Factor 1 & Factor 2 & & Factor 4 & Factor 5 \\
\hline $\mathrm{X} 11$ & Group members are active in the open discussion & .757 & & & & \\
\hline $\mathrm{X} 10$ & Group members are free to share their opinions in group & .729 & & & & \\
\hline $\mathrm{X} 12$ & Higher level of tolerant between group member & .679 & & & & \\
\hline X9 & Group member are active in sharing their ideas & .665 & & & & \\
\hline $\mathrm{X} 8$ & Each group member has their own responsibility & .595 & & & & \\
\hline $\mathrm{X} 13$ & Each group member has strong motivation & .594 & & & & \\
\hline X16 & Each group member active in group activities & .592 & & & & \\
\hline $\mathrm{X} 7$ & Each member understands the responsibility assigned & .559 & & & & \\
\hline $\mathrm{X} 17$ & The Level of attendance in every group meeting & .537 & & & & \\
\hline $\mathrm{X} 2$ & The relationship between group member and leader & & .856 & & & \\
\hline $\mathrm{X} 1$ & Relationship among group members & & .815 & & & \\
\hline X3 & Communication among group members & & .794 & & & \\
\hline $\mathrm{X} 4$ & The leader is leading with example & & .620 & & & \\
\hline X6 & The leader is willing to share resources & & .509 & & & \\
\hline X19 & Group member has good self-management & & & .786 & & \\
\hline $\mathrm{X} 20$ & Group member develop self-control & & & .748 & & \\
\hline $\mathrm{X} 18$ & Supportive member involvement & & & 645 & & \\
\hline $\mathrm{X} 21$ & Ethics are common practice in group activities & & & .643 & & \\
\hline X14 & Each member has their own capabilities & & & 460 & & \\
\hline $\mathrm{X} 23$ & Members are consisting of different cultures member & & & & .867 & \\
\hline $\mathrm{X} 24$ & Members have different skills & & & & .837 & \\
\hline $\mathrm{X} 22$ & Members have different knowledge contribution & & & & .602 & \\
\hline $\mathrm{X} 5$ & Group leader appointed by lecturers & & & & & .719 \\
\hline $\mathrm{X} 15$ & Group has outsider mentor other than group member & & & & & 697 \\
\hline
\end{tabular}

To know which factor is account for the most variance among the five factors mentioned above, can be seen in Table 4 explain 63.32 percent of the variance that contribute to the successful group performance from the perspective of business students. As shown in Table 4 factor that has highest variance is cohesiveness $(19.43 \%)$ while factor accounts the least variance is factor $5(6.44 \%)$ that is appointed team leader.

Table 4. Percentage of variance after varimax rotation

\begin{tabular}{cccccc}
\hline & Factor 1 & Factor 2 & Factor 3 & Factor 4 & Factor 5 \\
\hline Eigenvalues & 4.66 & 3.53 & 3.39 & 2.07 & 1.54 \\
\% of Variance & 19.43 & 14.73 & 14.13 & 8.60 & 6.44 \\
Cumulative \% & 19.43 & 34.15 & 48.28 & 56.88 & 63.32 \\
\hline
\end{tabular}

According on the result of this study, successful group performance based on the perspective of business students are the group that cohesive. Cohesiveness is the factor that contribute the most variance int the successful group performance. This finding consistent with Thompson, et al. [33], that found cohesive team leads to better group performance. Similarly, a study found that when the group more cohesive the group tend to handle conflict better, which affected the effectiveness of the group performance [34]. Moreover, group cohesiveness help the group members to be able to coordinate resources, shared knowledge and ideas which affected successful group performance [26]. In addition, more cohesive the group in achieving goals and ideas as a group, the more effective the group performance [35].

The second important factor contributes to successful group performance is the inter-relationship among group members and group leader. This study is consistent with Dachner and Polin [36] findings that stated undergraduate students are inter-dependence and value social-relationship in developing their selfconcept that help them to recognize their strength and weaknesses which motivate them to be active involve

Int. J. Eval. \& Res. Educ. Vol. 9, No. 4, December 2020: 896 - 902 
in collaborative group environment. Similarly, a study mentioned that assigning group based on students strength and weaknesses affected the performance of the group [37].

Norm is another factor that contribute to successful group performance in the perspective of business students. In designing groupwork lecturer need to advocate team norms as a contract behavior between students in a group to increase group performance [6]. Accordingly, Norms are important to be establish in groupwork environment because norms help group to collaborate in knowledge construction to improve the teamwork skills that eventually contribute to the effectiveness of group performance [18].

From the perspective of business students, the fourth factor that contribute to successful group performance is diversity. This finding consistent with a study Daly, et al. [38] shows that cultural diversity help student realizes different cultural knowledge that enhance their ability working with one another. Thus, contributes to their successful collaboration within group. The other study Curşeu and Pluut [18] found that diversity in expertise can lead to a good collaboration and better coordination between members in carrying out tasks that contribute to a successful group performance. Another study by Syahrial, et al. [39] found that in performing teamwork learning method, the teachers or lecturer must also understand the cultural diversity of the students to achieve a better group performance.

The last factor is appointed team leader. This findings however is contradict with the study of Mark [40] revealed the fact that in selecting group leader business students more likely to choose their own leader rather that appointed by the lecturers. On the other hand, this study found that group leader appointed by the lecturer has higher factor loading in building the last factor. Since their study conducted in USA there might be different perspective than Indonesian business student regarding the pointing of team leader.

\section{CONCLUSION}

Succesful group performance from a business student's perspective is consists of cohesiveness, inter-relationship, norm, diversity, and appointed team leader, are the most important factors. Each factor is constructed from some item variables that are correlated with each of those factors. In Cohesiveness, the item variables that constructed this factor are group member active in open discussion, free to share ideas, the higher level of tolerant; each group member has a responsibility, and have strong motivation. The relationship between group members and the relationship with the group leader is the item variables that highly correlate with the second factor which is inter-relationship. Self-management and self-control are the variables that account in the third factor which is named Norm. The fourth factor that gives a contribution to the successful group performance is diversity. Different cultures and different skills among group members are considered a significant variable for the fourth factor. The last factor that considers meaningful even though it has only consisted of two items variable is the appointed team leader. It can be concluded that in Indonesia, particularly for the business students of Universitas Klabat, they preferred the team leader appointed by the lecturer or mentor rather than by group members. The team leader appointed by the lecturer is considered significant for successful group performance.

This study was limited to 3rd and 4th years of undergraduate business students of Universitas Klabat, Indonesia. Furthermore, this study revealed five factors which are; cohesiveness, inter-relationship, norms, and diversity, and appointed team leader that contribute to the successful group performance. Further study may be conducted regarding group performance from the perspective of the other major students. A future study might also carry out.

\section{REFERENCES}

[1] S. B. Channon, et al, "What makes a 'good group'? Exploring the characteristics and performance of undergraduate student groups," Adv. Health Sci. Educ., vol. 22, no. 1, pp. 17-41, 2017.

[2] S. McMurray, M. Dutton, R. McQuaid, and A. Richard, "Employer demands from business graduates," Educ. Train., vol. 58, no. 1, pp. 112-132, 2016.

[3] M. Beer, et al., "Why Leadership Training Fails—and What to Do About It," Harv. Bus. Rev., pp. 1-9, Oct. 2016.

[4] B. Shola. F, et al, "The non-technical skills needed by graduates of technical colleges in metalwork technology," Int. J. Eval. Res. Educ., vol. 8, no. 4, pp. 654-658, 2019.

[5] N. Qomariyah, T. Savitri, T. Hadianto, and M. Claramita, "Formulating employability skills for graduates of public health study program," Int. J. Eval. Res. Educ., vol. 5, no. 1, pp. 22-31, 2016.

[6] L. Riebe, A. Girardi, and C. Whitsed, "A systematic literature review of teamwork pedagogy in higher education," Small Group Res., vol. 47, no. 6, pp. 619-664, 2016.

[7] S. Sugito, S. M. E. Susilowati, H. Hartono, and S. Supartono, "Enhancing students' communication skills through problem posing and presentation," Int. J. Eval. Res. Educ., vol. 6, no. 1, pp. 17-22, 2017.

[8] D. Bay and P. Pacharn, "Impact of group exams in a graduate intermediate accounting class," Account. Educ., vol. 26, no. 4, pp. 316-334, 2017. 
[9] R. Bravo, L. Lucia-Palacios, and M. J. Martin, "Processes and outcomes in student teamwork. An empirical study in a marketing subject," Stud. High. Educ., vol. 41, no. 2, pp. 302-320, 2016.

[10] M. C. Abas and O. A. Imam, "Graduates' competence on employability skills and job performance," Int. J. Eval. Res. Educ., vol. 5, no. 2, pp. 119-125, 2016.

[11] D. Fung and C. Howe, "Group work and the learning of critical thinking in the Hong Kong secondary liberal studies curriculum," Camb. J. Educ., vol. 44, no. 2, pp. 245-270, 2014.

[12] R. M. Grant and C. Baden-Fuller, "How to develop strategic management competency: reconsidering the learning goals and knowledge requirements of the core strategy course," Acad. Manag. Learn. Educ., vol. 17, no. 3, pp. 322-338, 2018.

[13] S. Kapitanoff and C. Pandey, "Colaborative testing in statistics: group interaction, anxiety, and class performance," Statistics Education Research Journal, vol. 17, no. 2, pp. 51-67, 2018.

[14] S. Lavy, "Who benefits from group work in higher education? An attachment theory perspective," High. Educ., vol. 73, no. 2, pp. 175-187, 2016.

[15] B. A. Ritter, E. E. Small, J. W. Mortimer, and J. L. Doll, "Designing management curriculum for workplace readiness: developing students' soft skills," J. Manag. Educ., vol. 42, no. 1, pp. 80-103, 2018.

[16] D. Soetanto and M. MacDonald, "Group work and the change of obstacles over time: The influence of learning style and group composition," Act. Learn. High. Educ., vol. 18, no. 2, pp. 99-113, 2017.

[17] M. Thoaele, C. Suhre, and A. Hofman, "Using technology-enhanced, cooperative, group-project learning for student comprehension and academic performance," Eur. J. Eng. Educ., vol. 41, no. 3, pp. 263-278, 2016.

[18] P. L. Curşeu and H. Pluut, "Student groups as learning entities: The effect of group diversity and teamwork quality on groups' cognitive complexity," Stud. High. Educ., vol. 38, no. 1, pp. 87-103, 2013.

[19] C. Wrigley and K. Straker, "Design Thinking pedagogy: the Educational Design Ladder," Innov. Educ. Teach. Int., vol. 54, no. 4, pp. 374-385, 2015.

[20] A. Tripathi, U. K. Bamel, H. Paul, D. Gordon, and N. Bamel, "Antecedents of competitive group formation intention in business education context," Int. J. Organ. Anal., vol. 26, no. 3, pp. 518-535, 2018.

[21] J. Cohen and C. Robinson, "Enhancing teaching excellence through team-based learning," Innov. Educ. Teach. Int., vol. 55, no. 2, pp. 133-142, 2017.

[22] B. E. Ashforth and F. Mael, "Social identity theory and the organization," Acad. Manage. Rev., vol. 14, no. 1, pp. 20-39, 1989.

[23] S. Lavy, "Who benefits from group work in higher education? An attachment theory perspective," High. Educ., vol. 73, no. 2, pp. 175-187, 2016.

[24] M. I. Hwang, "Relationship between teamwork and team performance: Experiences from an ERPsim competition," Journal of Information Systems Education, vol. 29, no. 3, pp. 157-168, 2018.

[25] N. Meslec and P. L. Curşeu, "Are balanced groups better? Belbin roles in collaborative learning groups," Learn. Individ. Differ., vol. 39, pp. 81-88, Apr. 2015.

[26] S. Chung, R. B. Lount, H. M. Park, and E. S. Park, "Friends with performance benefits: A meta-analysis on the relationship between friendship and group performance," Pers. Soc. Psychol. Bull., vol. 44, no. 1, pp. 63-79, 2018.

[27] M. Wu and Y.-H. Chen, "A factor Analysis on Teamwork Performance -an Empirical Study of Inter-instituted Collaboration," Eurasian J. Educ. Res., no. 55, pp. 37-54, 2014.

[28] R. Bravo, S. Catalán, and J. M. Pina, "Analysing teamwork in higher education: an empirical study on the antecedents and consequences of team cohesiveness," Stud. High. Educ., vol. 44, no. 7, pp. 1153-1165, 2018.

[29] M. Hoegl and H. G. Gemuenden, "Teamwork quality and the success of innovative projects: A theoretical concept and empirical evidence," Organ. Sci., vol. 12, no. 4, pp. 435-449, 2001.

[30] R. A. Asún, K. Rdz-Navarro, and J. M. Alvarado, "developing multidimensional likert scales using item factor analysis: The case of four-point items," Sociol. Methods Res., vol. 45, no. 1, pp. 109-133, 2016.

[31] A. Field, Discovering statistics using SPSS, 2nd ed, London: Sage, 2005.

[32] A. G. Yong and S. Pearce, "A beginner's guide to factor analysis: focusing on exploratory factor analysis," Tutor. Quant. Methods Psychol., vol. 9, no. 2, pp. 79-94, 2013.

[33] B. M. Thompson, et al., "Team cohesiveness, team size and team performance in team-based learning teams," Med. Educ., vol. 49, no. 4, pp. 379-385, 2015.

[34] K. J. Chapman, M. L. Meuter, D. Toy, and L. K. Wright, "Are student groups dysfunctional?: Perspectives from both sides of the classroom," J. Mark. Educ., vol. 32, no. 1, pp. 39-49, 2010.

[35] J. Cumming, et al, "Development and validation of the groupwork skills questionnaire (GSQ) for higher education," Assess. Eval. High. Educ., vol. 40, no. 7, pp. 988-1001, 2015.

[36] A. M. Dachner and B. Polin, "A systematic approach to educating the emerging adult learner in undergraduate management courses," J. Manag. Educ., vol. 40, no. 2, pp. 121-151, 2016.

[37] S. H. (Mark) Lee, et al, "What do students think about group work in business education? An investigation into the benefits, challenges, and student-suggested solutions," J. Educ. Bus., vol. 91, no. 7, pp. 380-386, 2016.

[38] A. Daly, S. Hoy, M. Hughes, J. Islam, and A. S. Mak, "Using group work to develop intercultural skills in the accounting curriculum in Australia," Account. Educ., vol. 24, no. 1, pp. 27-40, 2015.

[39] S. Syahrial, et al., "The impact of etnocontructivism in social affairs on pedagogic competencies," Int. J. Eval. Res. Educ., vol. 8, no. 3, pp. 409-416, 2019.

[40] M. B. Marks and A. H. O'Connor, 'Understanding students' attitudes about group work: What does this suggest for instructors of business?” J. Educ. Bus., vol. 88, no. 3, pp. 147-158, 2013. 